\title{
Aplicação da semântica das condições de verdade à redação das definições nos dicionários semasiológicos
}

\author{
Application of truth-conditional semantics to the \\ writing of definitions in semasiological dictionaries
}

Virginia Sita Farias*

Universidade Federal do Rio Grande do Sul - UFRGS

Porto Alegre - Rio Grande do Sul / Brasil

\begin{abstract}
RESUMO: Uma teoria da definição lexicográfica deve estar amparada em três parâmetros: (1) uma taxonomia de paráfrases definidoras, (2) um padrão sintático e (3) um modelo semântico. Este trabalho trata do terceiro parâmetro. O estudo analisa a aplicação da semântica das condiçōes de verdade à redação das definiçôes lexicográficas, tendo em vista: (a) avaliar as contribuiçōes desse modelo teórico para a elucidação do significado das unidades léxicas; e (b) determinar seus limites em relação à redação das paráfrases definidoras.
\end{abstract}

PALAVRAS-CHAVE: Lexicografia, Definição lexicográfica, Semântica das condições de verdade.

ABSTRACT: A theory of the lexicographic definition should be supported by three parameters: (1) a taxonomy of explanatory paraphrases, (2) a syntactic pattern, and (3) a semantic model. This paper deals with the third parameter. The study aims at analyzing the application of truth-conditional semantics to the writing of lexicographic definitions, in order to: (a) evaluate the contributions of this theoretical model to the elucidation of the meaning of lexical units, and (b) determine its limitations in relation to the writing of explanatory paraphrases.

KEYWORDS: Lexicography, Lexicographic definition, Truth-conditional semantics.

\section{Introdução}

É praxe apontar o significado como a informação mais procurada pelos consulentes nos dicionários semasiológicos ${ }^{1}$ (cf., p.ex., HARTMANN, 2001,

\footnotetext{
*virginiafarias@terra.com.br. Bolsista de doutorado CNPq.

${ }^{1}$ A distinção entre semasiologia e onomasiologia fundamenta-se no ponto de partida do ato da consulta, o significante ou o significado, respectivamente (cf. BALDINGER, 1985, p. 42-43), e possibilita estabelecer uma oposição entre dicionários semasiológicos
} 
p. 82; JACKSON, 2002, p. 71). Por essa razão, ainda que o programa constante de informações dessas obras costuma ser bastante extenso, ${ }^{2}$ o cerne da microestrutura é, indubitavelmente, o comentário semântico, ${ }^{3}$ e, mais precisamente, dentro dele, a definição. Entretanto, e não obstante a abundância de estudos que, ao longo de muitos anos, vêm abordando o problema da definição sob as mais diversas perspectivas (cf., p. ex., ZGUSTA, 1971, p. $252-$

e onomasiológicos. Os dicionários semasiológicos têm como principal característica apresentar paráfrases definidoras, ao passo que os dicionários onomasiológicos distinguem-se pelo estabelecimento de relaçôes conceituais entre as palavras, a exemplo do thesaurus, dos dicionários de sinônimos / antônimos, dos dicionários pela imagem, ou mesmo dos dicionários bilíngues (cf. HARTMANN; JAMES, 2001, s.v. semasiological dictionary; s.v. onomasiological dictionary).

${ }^{2}$ Wiegand (1989a, p. 433) enumera 62 diferentes tipos de informaçōes lexicográficas de caráter linguístico passíveis de constar como segmentos microestruturais em dicionários semasiológicos. Esse número inicial, por sua vez, é ampliado em Wiegand (1989b, p. 468), com a descrição de 90 diferentes tipos de informaçōes. De acordo com Farias (2009a, p. 129-131), a seleção dos segmentos que devem conformar o programa de informações microestruturais de uma dada obra lexicográfica precisa levar em conta ao menos três fatores: (a) a língua descrita, haja vista o fato de que alguns fenômenos são pertinentes apenas a algumas línguas (por exemplo, os morfemas de caso em dicionários de línguas declináveis; a duração dos sons vocálicos como traço distintivo em línguas como o alemão, o inglês e o latim); (b) a categoria morfológica do signo-lema, considerando que as informaçôes em um verbete relativo a um verbo e um verbete relativo a um substantivo são bastante diferentes; e (c) o tipo de dicionário, tendo em vista que a funcionalidade das informaçôes deve ser medida em relação à função que a obra deve cumprir e ao seu usuário (cf. BUGUEÑO MIRANDA; FARIAS, 2006; 2008). A seguir, apresentamos um exemplo de verbete com um programa de informaçôes extenso:

nạch $\bullet$ wei $\bullet$ sen (hat) Vt1. etw. $n$. (mitDokumenten) zeigen, dass man etw.hat (einfestes Einkommen, e-n festen Wohnsitz n.r 2. etw. $n$. mit Argumenten od. Dokumentenzeigen, dass das, was man behauptet, wahrist: die Existenz von etw. n.; Zusammenhänge n. 3. j-metw. n. beweisen, dassj-d etw. getan hat (j-m e-n Mord, e-n Dienstahl n.) \| hierzu nach•weis•bar $\operatorname{Adj}(\mathrm{LaGWDaF}, 2008)$

${ }^{3}$ A distinção entre comentário de forma [Formkommentar] e comentário semântico [semantischerKommentar] é estabelecida com base em Wiegand (1989a, p. 434-440) e fundamenta-se na concepção saussuriana do signo linguístico. Assim, pois, o comentário de forma comporta informações relativas à representação gráfica e fonético-fonológica do signo-lema, enquanto o comentário semântico abriga informaçóes referentes ao seu significado. A esse respeito, cf. também Hausmann; Wiegand (1989, p. 340-357), Hartmann; James (2001, s.v. comment) e Bugueño Miranda (2004). 
263; DUBOIS; DUBOIS, 1971, p. 84-89; HAENSCH et al., 1982, p. $259-$ 285; SVÉNSEN, 1993, p. 112-139; LANDAU, 2001, p. 153-189; SECO, 2003, p. 25-58; GEERAERTS, 2003; RUNDELL, 2008), ainda não existe o que poderíamos chamar de uma "teoria da definição lexicográfica" (cf. BUGUEÑO MIRANDA, 2009). A formulação das paráfrases definidoras está, portanto, subordinada à habilidade de redação do lexicógrafo. Assim sendo, não surpreende o fato de que os resultados obtidos nem sempre sejam completamente satisfatórios: ${ }^{4}$

schifoso agg. Che faschifo [...] (PCDIt, 2009).

íngua $s f$. Med. 1. Ingurgitamento do gânglio linfático inguinal. [...]. (MiAu, 2008).

novio, -a [...] 2 Con respecto a una persona, otra que mantiene com ella relaciones amorosas com intención de casarse con ella. [...] (DUEe, 2001).

Anakonda [...] die; -, -s; südamerikanischeungiftige Riesenschlange. (NDW, 2007).

Os exemplos apresentados acima ilustram as três principais categorias de inadequaçōes definitórias descritas em Bugueño Miranda; Farias (2009, p. 5968): (a) metodológicas, caracterizadas pelo descumprimento de parâmetros definitórios elementares 5 (p.ex., a definição circular s.v. schifoso); (b) redacionais, que incluem problemas como a seleção vocabular e a formulação sintática da paráfrase definidora (p.ex., s.v. ingua e s.v. novio,-a), e (c) semânticas, causadas falta de correspondência entre o conteúdo sêmico da unidade definida e o conteúdo sêmico da paráfrase definidora (p.ex., s.v. Anakonda).

$\mathrm{O}$ ato de definir implica dois processos complementares: (a) a apreensão do conteúdo semântico da unidade léxica e (b) sua explicitação por meio de uma formulação linguística. A obtenção de paráfrases suficientemente elucidativas, por sua vez, depende de dois fatores concomitantemente, quais sejam, a natureza do significado da unidade léxica a ser definida e a obediência

\footnotetext{
${ }^{4}$ Seguindo a tendência da metalexicografia europeia para as citaçōes de dicionários, em vez da Harvard Citation (autor, ano, página), usaremos abreviaturas (cf. HARTMANN, 2001, p. 11).

${ }^{5}$ A esse respeito, cf. Martínez de Souza (1995, s.v. definición lingüística), Landau (2001, p. 157-171), Medina Guerra (2003, p. 132-138) e Seco (2003, p. 30-33).
} 
a determinados princípios de redação (cf. BUGUEÑO MIRANDA; FARIAS, 2011a). Em vista disso, Bugueño Miranda (2009) propõe que uma "teoria da definição lexicográfica" deve fundamentar-se em três parâmetros: (1) uma taxonomia de paráfrases definidoras; (2) um padrão sintático, e (3) uma teoria semântica. O escopo deste trabalho recai, justamente, sobre o terceiro parâmetro arrolado. ${ }^{6}$

Uma teoria semântica constitui um instrumento heurístico para estabelecer que tipos de informaçóes devam ser explicitadas no momento de redigir a paráfrase definidora. Assim sendo, o modelo semântico atua especialmente no primeiro processo pertinente ao ato de definir, uma vez que determina sob que prisma o significado deverá ser compreendido. Engelberg; Lemnitzer (2004, p. 8) apontam, como teorias que se destacam no âmbito da (meta)lexicografia, a análise componencial, a semântica prototípica e a semântica das condições de verdade. Na presente ocasião, tratar-se-á, especificamente, da relação entre a semântica das condiçóes de verdade e a definição nos dicionários semasiológicos. ${ }^{7}$ Este estudo, pois, objetiva analisar de que forma a semântica das condições de verdade se aplica à redação das paráfrases definidoras, a fim de determinar (a) em que medida os subsídios teóricos desse modelo semântico podem contribuir para o poder elucidativo da paráfrase definidora (comparativamente aos demais modelos), e (b) quais são as suas limitações no que diz respeito ao fazer lexicográfico.

\section{A semântica das condições de verdade como mecanismo heurístico de apreensão do significado}

A semântica das condições de verdade parte do princípio de que conhecer o significado de uma dada sentença é conhecer as condiçôes sob as quais ela é verdadeira (cf. CHIERCHIA; McCONELL-GENET, 2000, p. 53-110; ALLWOOD et al., 2001, p. 15-93). Entretanto, também é possível estabelecer condições de verdade em termos de indivíduos, coisas, eventos, conjunturas etc., no mundo (ou em um mundo possível). Nesse caso, lidase com as respectivas categorias em termos de suas extensōes (cf. PALMER, 2001, p. 195-206).

\footnotetext{
${ }^{6}$ Sobre os demais parâmetros, cf. Bugueño Miranda (2009), Farias (2009a, p. 164-214) e Bugueño Miranda; Farias (2011a).

${ }^{7}$ Sobre a aplicação da análise componencial e da semântica dos protótipos à elaboração das definiçōes, cf. Farias (2009a, p. 167-185; 2009b) e Bugueño Miranda; Farias (2011a).
} 
Para cumprir os objetivos propostos, é necessário, antes de tudo, enumerar e descrever brevemente os princípios da semântica das condições de verdade atinentes à elaboração das definições. Tais princípios são: (a) a noção de categorização, (b) as noções de intensão e extensão e (c) a relação entre implicação e equivalência de sentenças.

\section{Categorização}

Por meio da determinação do gênero, da espécie e das diferenças, Aristóteles propunha definir a essência das coisas (cf. Categorias 5, 2a11-3b24). $\mathrm{Na}$ sua concepção, a definição não tinha como finalidade o reconhecimento de objetos pertencentes à mesma classe, mas o reconhecimento da essência de um objeto. Entretanto, a definição aristotélica tem como consequência a classificação dos objetos e sua categorização em relação a outros. Quando se define homem como "animal racional", não somente se assevera algo sobre a essência de homem (a de ser um animal racional) mas também se reconhece homem como classe (a classe dos homens é formada por todos os seres que são animais racionais). Ao mesmo tempo, por meio do gênero "animal" e da diferença "racional", incluise homem em uma categoria (cf. LARA, 1996, p. 208).

Taylor (2009, p. 21) expõe sinteticamente os princípios sobre os quais se assenta a teoria clássica da categorização:

a) as categorias são definidas em termos de uma conjunção de traços necessários e suficientes;

b) os traços são binários;

c) todos os membros de uma categoria têm igual representatividade;

d) as categorias possuem fronteiras claramente delimitadas.

O primeiro princípio preconiza que, para decidir se uma determinada entidade pertence a uma dada categoria, deve-se observar se ela possui os traços, atributos ou condiçôes, que constituem o seu denominador comum. Conforme Taylor (2009), os traços são necessários, na medida que, se um deles não é exibido por uma determinada entidade, então essa entidade não pode ser considerada membro da categoria. Conjuntamente, por sua vez, os traços são suficientes, visto que, se uma determinada entidade exibe cada um dos traços definidos para uma dada categoria, então ela é membro da categoria. A soma dos traços, em consonância com o modelo aristotélico, define a essência da categoria. A categorização, sob esta perspectiva, responde a um modelo de condiçōes necessárias e suficientes. Nesse sentido, o conjunto de condições 
necessárias e suficientes para que uma entidade xpertença à categoria $Y$ corresponde ao significado da palavra ' $Y$ ' (cf. KLEIBER, 2004, p. 23).

De acordo com o segundo princípio, os traços são binários. Isso significa que um traço ou está envolvido na definição de uma categoria, ou não está; uma entidade ou possui determinado traço, ou não o possui. Cada traço, pois, pode assumir apenas um valor: ou presente [+], ou ausente [-] (cf. TAYLOR, 2009, p. 21). O já clássico exemplo de bachelor ilustra bem a aplicação do sistema de traços à análise semântica. A essência dessa categoria poderia ser definida por meio dos traços [HUMANO], [MASCULINO], [ADULTO] e [SOLTEIRO], que se opõem, binariamente, aos traços [-HUMANO], [FEMININO], [-ADULTO] e [CASADO]. Taylor (2009, p. 28-29) aponta três vantagens da aplicação desse método em semântica. Em primeiro lugar, a análise dos traços permite contrastar pares de palavras relacionadas entre si. Nesse sentido, Engelberg; Lemnitzer (2004, p. 10) afirmam que "as reflexōes da semântica das condições de verdade deixam claro para nós o potencial de referência das palavras e abrangem as relações semânticas entre lexemas". ${ }^{8}$ Assim, pois, no inglês, o significado de bachelor inclui o significado de man; man é superordenado (ou hiperônimo) de bachelor, ao passo que bacheloré subordinado (ou hipônimo) de man. ${ }^{9}$ Em segundo lugar, os traços possibilitam a definição de "classes naturais" [natural classes] de itens (p.ex., o traço [-ANIMADO] define a classe dos nomes inanimados). A definição das classes naturais, por sua vez, está intimamente relacionada com o estabelecimento de "restriçōes de seleção" [selectionalrestrictions] (cf. TAYLOR, 2009, p. 28), ou seja, as restrições atinentes à combinação das unidades léxicas em sintagmas (p.ex., o adjetivo insípido pode ser atribuído apenas a nomes com o traço [-ANIMADO]). Por fim, em terceiro lugar, o sistema de traços pode lançar luz sobre determinados tipos de relações de sentido estabelecidas entre sentenças (p.ex., a sinonímia e o acarretamento).

Em relação ao terceiro postulado, são necessárias algumas ressalvas. As críticas recebidas são devidas ao fato de que o modelo das condições necessárias e suficientes tem um poder explicativo forte, porém um poder descritivo fraco

\footnotetext{
8 [die Überlegungen der wahrheitskonditionalen Semantik erschlieâen uns das referentielle Potenzial von Wörtern und erfassen semantische Relationen zwischen Lexemen]

${ }^{9}$ A possibilidade de organização hierárquica do léxico evidencia uma analogia com a semântica estruturalista (cf. KLEIBER, 2004, p. 31-32). A diferença substancial reside no fato de que, na visão da lógica, as relações estabelecidas entre as palavras refletem a organização da realidade extralinguística, ao passo que, na visão do estruturalismo, as relações são estabelecidas no interior do sistema linguístico (cf. LYONS, 1989, p. 318-319).
} 
(cf. KLEIBER, 2004, p. 31-37). Com efeito, a teoria explica de forma satisfatória a pertinência de uma dada entidade a uma categoria determinada, em função da presença dos traços definidores dessa categoria. Entretanto, no que concerne especificamente às espécies naturais (plantas, animais etc.), o modelo mostra-se bastante débil na tentativa de descrevê-las. Por exemplo, o conjunto de condições necessárias e suficientes para a pertinência à categoria ave, quais sejam, 'ser um animal', 'possuir um bico', 'ter o corpo coberto de penas', 'possuir asas', 'pôr ovos', não se aplica de forma homogênea ao conjunto das aves existentes. Dito de outra forma, o modelo permite descrever satisfatoriamente a categoria ave do ponto de vista intensional, mas não consegue determinar a sua extensão. Wittgenstein (2003) já antecipava algumas inadequações da teoria clássica da categorização. Ao analisar a categoria jogos [Spiele], o autor atenta para o fato de que haveria "uma rede complexa de semelhanças, que se cruzam e se sobrepõem umas às outras" (WITTGENSTEIN, 2003, p. 57). ${ }^{10}$ Dessa forma, ao contrário do que preconiza a teoria clássica, uma categoria não seria estruturada em termos de traços compartilhados, mas de um cruzamento de traços. Haveria atributos tipicamente associados a uma categoria: alguns membros compartilhariam alguns desses atributos, outros membros compartilhariam outros atributos. A essas similaridades, Wittgenstein (2003) chama "semelhanças de família" [Familienähnlichkeiten]. Posteriormente, e de forma abertamente reacionária ao modelo clássico, Rosch (1978) procura demonstrar que as categorias não são compostas por membros detentores do mesmo status, mas, pelo contrário, há membros dentro de uma categoria que são julgados como mais centrais que outros. Essa assimetria, chamada de "efeito de prototipicidade" [prototypicality effect] (cf. GEERAERTS, 2001), é encontrada, por exemplo, na categoria ave, da qual pardal e águia são membros mais prototípicos do que avestruz e pinguim.

Por fim, em relação ao quarto princípio, Kleiber (2004, p. 27) argumenta que o modelo das condiçóes necessárias e suficientes responde a uma dupla intuição: (a) o significado de uma palavra é algo que se deixa determinar com relativa precisão e (b) as categorias são entidades discretas que se diferenciam nitidamente. Essa visão de categoria, contudo, é alvo de críticas. No âmbito da semântica cognitiva, a categorização é entendida como não criterial, ou seja, não responde a uma simples relação de pertinência ou não a uma determinada categoria em função de suas condições criteriais. Dessa forma,

${ }^{10}$ [einkompliziertes Netz von Ähnlichkeiten, die einanderübergreifen und kreuzen] 
e tendo em vista, como vimos, que os membros dentro de uma categoria não gozariam do mesmo status, as categorias não poderiam apresentar fronteiras nítidas (cf. EVANS; GRENN, 2006, p. 28-29).

\section{Intensão e extensão}

O modelo das condições necessárias e suficientes está em consonância com o princípio fregeano, segundo o qual a intensão determina a extensão.

$\mathrm{Na}$ lógica formal, entende-se que as sentenças descrevem um determinado "estado de coisas" [state of affairs] no mundo. O "estado de coisas" denotado pela sentença corresponde ao seu valor de verdade, que pode ser verdadeiro ou falso, segundo o mundo se apresente ou não conforme é descrito. O valor de verdade, por sua vez, equivale ao significado da sentença. Dessa maneira, duas sentenças terão o mesmo significado, sempre e quando sejam ambas ou verdadeiras ou falsas (cf. CHIERCHIA; McCONELL-GENET, 2000, p. 55-65).

Nesse contexto, Frege (2008) introduz a noção de "sentido" [Sinn], que se opõe à de "referência" [Bedeutung].$^{11} \mathrm{~A}$ referência corresponde ao que é designado por um signo (nome, expressão, sentença), ao passo que o sentido é o que está contido no "modo de apresentação" [Art des Gegebenseins] do objeto $^{12} \mathrm{~A}$ referência de um nome é o indivíduo ao qual a designação se aplica, ao passo que a referência de uma sentença é o seu valor de verdade. O sentido, portanto, entra em jogo para ajudar a diferenciar signos que possuam a mesma referência. Para ilustrar, Frege (2008, p. 24) menciona as designações "estrela

\footnotetext{
${ }^{11}$ Empregamos os termos sentido e referência, já consagrados em diversas tradições linguísticas (p.ex., inglês senselreference, espanhol sentido / referencia), como equivalentes dos termos fregeanos Sinn e Bedeutung, respectivamente. O termo alemão Bedetung, no uso não técnico, equivale a significado. Lyons (1989, p. 199) não deixa de chamar a atenção para a escolha "infeliz" [unfortunate] de G. Frege. Essa escolha, de acordo com Lyons (1989), deve-se a que os filósofos, de um modo geral, pensam em "referência" como uma relação semântica básica. $\mathrm{O}$ autor ainda acrescenta que o alemão disporia de termos mais precisos para expressar os conceitos em questão, quais sejam, o próprio Bedeutung, que exprimiria de forma mais exata a noção fregeana de Sinn, e Bezeichnung "designação", que substituiria o termo fregeano Bedeutung.

${ }^{12}$ Chierchia; McConell-Genet (2000, p. 65-66) atentam para o fato de que distinções análogas à de G. Frege já haviam sido elaboradas anteriormente. A mais famosa delas é, certamente, no âmbito da linguística, a dicotomia saussuriana significante/ significado.
} 
d'alva" [Morgenstern] e "estrela vespertina" [Abendstern]. Ambas teriam a mesma referência (o planeta Vênus), mas não o mesmo sentido, uma vez que cada expressão refere a uma determinada propriedade da referência.

Um signo (nome, expressão, sentença), portanto, une referência e sentido, ${ }^{13}$ de tal forma que

[a] conexão regular entre o signo, seu sentido e sua referência é tal que, ao signo, corresponde um sentido determinado, e a este, por sua vez, uma referência determinada, ao passo que a uma referência (a um objeto) não corresponde apenas um signo. $\mathrm{O}$ mesmo sentido tem diferentes expressōes em diferentes línguas, e, inclusive, na mesma. (FREGE, 2008, p. 25). ${ }^{14}$

Carnap (1988) reformula a dicotomia fregeana sentido / referência em termos de intensão / extensão. O autor desenvolve um método de análise do significado aplicado às expressōes denominadas "designadores" [designators]. Os designadores abrangem as sentenças declarativas, as expressóes individuais (constantes individuais ou descriçōes individuais) e os predicadores (constantes de predicados ou expressóes de predicado composto). Carnap (1988, p. 1) considera que "se dois designadores são equivalentes, nós também dizemos que eles têm a mesma extensão. Se eles são, além disso, L-equivalentes [i.e., logicamente equivalentes], nós dizemos que eles têm a mesma intensão $0 .{ }^{15} \mathrm{~A}$ extensão de uma sentença declarativa corresponde ao seu valor de verdade, enquanto sua intensão corresponde à proposição expressa por ela. A extensão de uma expressão individual, por sua vez, corresponde ao indivíduo ao qual ela se refere, e sua intensão, ao conceito por meio do qual o objeto é

${ }^{13}$ Frege (2008, p. 25), contudo, não deixa de mencionar que o fato de se ter um sentido não assegura que haverá necessariamente uma referência. Com efeito, há expressōes como "o habitante de Marte", que possuem um sentido, mas para as quais, pelo menos até o momento, não é possível assegurar que haja também uma referência.

${ }^{14}$ [Die regelmäßige Verknüpfungzwischendem Zeichen, dessen Sinnunddessen Bedeutungistderart, daßdem Zeicheneinbestimmter Sinnunddiesemwiedereinebestimmte Bedeutungentspricht, währendzueiner Bedeutung (einem Gegenstande) nichtnurein Zeichenzugehört. Derselbe Sinn hat in verschiedenen Sprachen, jaauch in derselbenverschiedene Ausdrücke]

15 [If two designators are equivalent, we say also that they have the same extension. If they are, moreover, L-equivalent, we say that they have also the same intension] 
identificado. Por fim, a extensão de um predicador equivale à classe de indivíduos aos quais ele se aplica, ao passo que sua intensão corresponde à propriedade expressa.

Tarski (1944, p. 345) afirma que "Semântica é uma disciplina que, genericamente falando, lida com certas relaçôes entre expressões de uma língua e os objetos (ou "estado de coisas") "referidos" por essas expressôes". ${ }^{16}$ Dessa forma, e em consonância com o exposto nos parágrafos precedentes, o significado é entendido em termos de uma correspondência com a realidade extralinguística, ou, em outras palavras, em função das suas condições de verdade (em se tratando de sentenças), ou das condiçóes necessárias e suficientes para o pertencimento a uma determinada categoria (em se tratando de expressóes referenciais). Isso permite concluir que o significado, no âmbito da semântica das condições de verdade, é compreendido extensionalmente. Esse fato evidencia uma clara oposição à semântica estrutural, no âmbito da qual, o significado é entendido intensionalmente, ou seja, está circunscrito a uma língua funcional ${ }^{17}$ e é determinado essencialmente pelos limites estabelecidos no interior do campo semântico correspondente, e não pela referência à entidade no mundo real designada pelo signo em questão (cf. DUPUY-ENGELHARDT, 1995; HILTY, 1997, p. 64-65; ENGELBERG; LEMNITZER, 2004, p. 9). Por outro lado, a compreensão extensional do significado representa um ponto de convergência com a teoria dos protótipos. Esta última, por tratar-se de uma teoria baseada no experimentalismo psicocognitivo, propõe a organização dos conceitos e de suas designações com base na apreensão do mundo pelo indivíduo (cf. HILTY, 1997, p. 65-66; ENGELBERG; LEMNITZER, 2004, p. 8-9).

De acordo com Kleiber (2004, p. 26), um duplo paralelismo resume a relação entre intensão / extensão e a categorização no modelo das condições necessárias e suficientes. Por um lado, estabelece-se uma relação entre uma intensão, entendida como uma conjunção suficiente de condições necessárias, e uma extensão, que corresponde a uma categoria com fronteiras nitidamente

\footnotetext{
16 [Semantics is a discipline which, speaking loosely, deals with certain relations between expressions of a language and the objects (or "states of affairs") "referred to" by those expressions]. Os destaques estão no texto original.

${ }^{17}$ Língua funcional é uma variedade interna da língua histórica, delimitada diacrônica (variação no decorrer do tempo), diatópica (variação no espaço geográfico), diastrática (variação de estratos socioculturais da comunidade linguística, o que inclui, por exemplo, as gírias) e diafasicamente (variação nos níveis de fala, por exemplo, coloquial, familiar, literário, poético) (cf. COSERIU, 1967).
} 
delimitadas. Por outro lado, a uma intensão composta de traços independentes e equivalentes (posto que um é tão necessário quanto o outro), corresponde uma extensão composta por membros que apresentam um status equivalente no seio de uma categoria.

\section{Implicação e equivalência de sentenças}

A lógica proposicional trata das relações estabelecidas entre sentenças simples por meio dos conectivos sentenciais ou proposicionais $(e, o u, s e \ldots$, então..., etc.), bem como da negação (não éo caso que), buscando estabelecer as suas condições de verdade. As relações mais estudadas são a negação, a conjunção, a disjunção e a implicação (cf. ALLWOOD et al., 2001, p. 26). Tendo em vista o objetivo deste trabalho, interessa-nos, especificamente, a relação de implicação. ${ }^{18}$

Uma implicação, ou sentença condicional, é obtida pela combinação de duas sentenças por meio dos conectivos "se..., então...", de tal forma que a oração introduzida por "se..." é chamada de antecedente, e a oração introduzida por "então...", consequente. Em uma relação de implicação, não se dá o caso em que $\mathrm{o}$ antecedente seja verdadeiro e o consequente falso. Apresentamos, a seguir, a tabela-verdade dessa relação:

\begin{tabular}{c|c|c}
$p$ & $\rightarrow$ & $q$ \\
\hline $\mathrm{V}$ & $\mathrm{V}$ & $\mathrm{V}$ \\
$\mathrm{V}$ & $\mathrm{F}$ & $\mathrm{F}$ \\
$\mathrm{F}$ & $\mathrm{V}$ & $\mathrm{V}$ \\
$\mathrm{F}$ & $\mathrm{V}$ & $\mathrm{F}$
\end{tabular}

Em matemática, a implicação é especialmente empregada na formulação de teoremas. Nesse caso, o antecedente é chamado de hipótese, e o consequente, de conclusão. A hipótese implica, ou tem como consequência, a conclusão; inversamente, a conclusão segue da hipótese (cf. TARSKI, 1995, p. 28-31). Observemos a tabela-verdade a seguir:

${ }^{18}$ Sobre as demais relações, cf. Allwood et al. (2001, p. 30-41). 


\begin{tabular}{l|c|c}
$p$ & $\longleftrightarrow$ & $q$ \\
\hline $\mathrm{V}$ & $\mathrm{V}$ & $\mathrm{V}$ \\
$\mathrm{V}$ & $\mathrm{F}$ & $\mathrm{F}$ \\
$\mathrm{F}$ & $\mathrm{F}$ & $\mathrm{V}$ \\
$\mathrm{F}$ & $\mathrm{V}$ & $\mathrm{F}$
\end{tabular}

Quando duas sentenças estão acopladas por meio do conectivo "se, $e$ somente se", o resultado da sentença composta é uma equivalência. Essa será verdadeira se os lados esquerdo e direito são ou ambos verdadeiros, ou ambos falsos. Uma relação de equivalência entre sentenças, portanto, deve ser analisada como uma implicação dupla (cf. tabela-verdade ad supra). Desse modo, cada sentença conforma uma condição necessária e suficiente para a outra.

Segundo Tarski (1995, p. 33), o conectivo "se, e somente se" é usado muito frequentemente para estabelecer definições. Segundo o autor ${ }_{2}$ toda definição pode assumir a forma de uma equivalência entre definiendum e definiens. No âmbito da lexicografia, a relação de equivalência ou igualdade entre o definiendum (signo-lema) e o definiens (paráfrase definidora) é chamada de "equação sêmica" [ecuación sémica] (cf. LARA, 1996).

Rey (1977, p. 100), adaptando o triângulo de Ogdene Richards, evidencia que uma definição deve, ao mesmo tempo, descrever um significado e apontar, ainda que indiretamente, para um referente extralinguístico. Em outras palavras, independentemente da teoria subjacente à sua formulação, uma definição analítica (como é o caso da definição por genus proximum + differentiae specificae) deve apresentar um viés intensional e um viés extensional. O definiens, uma vez que corresponde a um conjunto suficiente de condiçōes necessárias para que uma entidade xpertença à categoria $Y$, expressa a intensão do definiendum. A equivalência entre definiendum e definiens, no entanto, será estabelecida se, $\mathrm{e}$ somente se, a proposição expressa pelo definiens possuir exatamente a mesma referência (extensão) que o definiendum. Desse modo, poder-se-ia sustentar o argumento de que, na formulação de uma definição elucidativa, a extensão desempenha um papel mais importante que a intensão.

\section{Análise da aplicação do modelo das condições de verdade à formulação das definições}

A dificuldade de se formular uma definição objetiva de definição se deve, por um lado, à ausência de um consenso a respeito do que se entende por 
"conteúdo semântico" ou "significado" de uma expressão linguística (cf. BUGUEÑO MIRANDA; FARIAS, 2011b), e, por outro lado, à existência de uma variada gama de possibilidades de reescrita desse "conteúdo semântico" (cf. BOSQUE, 1982; BUGUEÑO MIRANDA, 2009). Remetemo-nos, dessa forma, aos dois processos inerentes ao ato de definir, descritos no início deste trabalho: a apreensão e a explicitação, por meio de uma paráfrase, do conteúdo semântico de uma unidade léxica.

O primeiro problema mencionado, que nos interessa sobremaneira neste trabalho, está intimamente relacionado à escolha de uma teoria semântica a partir da qual o significado possa ser compreendido e apreendido. A semântica das condiçôes de verdade, como vimos, é uma teoria de cunho extensional, que compreende o significado por meio da referência à realidade extralinguística.

O segundo problema, por sua vez, diz respeito à seleção de uma técnica definitória e ao estabelecimento de um padrão sintático. Para tanto, é preciso levar em conta o tipo de unidade léxica definida (cf. BUGUEÑO MIRANDA; FARIAS, 2011a). Na presente ocasião, trataremos apenas de substantivos concretos. Selecionaremos preferencialmente definições analíticas (cf. BUGUEÑO MIRANDA, 2009, p. 249), redigidas em metalinguagem de conteúdo (cf. SECO, 2003). ${ }^{19} \mathrm{Na}$ maioria dos casos, a técnica definitória corresponderá à definição por genus proximum + differentia especificae, que, sabe-se, é conhecida desde Aristóteles (cf. WEINRICH, 1979, p. 328).

\section{Aportes da semântica das condições de verdade à formulação das definições}

Uma definição formulada a partir dos subsídios teóricos da semântica das condiçōes de verdade, a nosso ver, deveria (a) efetuar uma categorização, (b) preocupar-se em corresponder à verdade em um dado modelo de mundo e (c) estabelecer uma equivalência entre definiendum e definiens. Analisemos as paráfrases transcritas a seguir:

\footnotetext{
${ }^{19}$ Seco (2003) distingue entre "metalinguagem de signo" [metalenguaje de signo] (referese à unidade léxica enquanto significante) e "metalinguagem de conteúdo" [metalenguaje de contenido] (refere-se ao significado da unidade léxica). Assim, ao contrário das definições em metalinguagem de conteúdo, as definições em metalinguagem de signo não se deixam submeter à prova da substituição (como ocorre, frequentemente, com as paráfrases de conjunções, preposições e adjetivos relacionais).
} 
homem n.m. 1 mamífero primata, bípede, que se distingue dos outros animais pela capacidade de produção de linguagem articulada e desenvolvimento intelectual [...] (DILP, 2010).

hombre. m. 1. Ser animado racional. [...] (DPRAE, 2007).

homme [...] Être (mâle ou femelle) appartenant à l'espèce animale la plus évoluée de la Terre, mammifère primate de la famille des hominidés*, seul représentant de son espèce [...] (PRobE, 2001).

Mensch'1 der; -en, -en 1. nur Sg.; das Lebewesen, das sprechen und denken kann u. sich dadurch vom Tier unterscheidet; [...] (LaGWDaF, 2008).

As quatro paráfrases estão formuladas sob o princípio de genus proximum + differentiae specificae. Sendo assim, conformam uma categorização. Essa categorização, como sabemos, é feita por meio da apresentação de um conjunto suficiente de condiçôes necessárias para o pertencimento a uma dada categoria, no caso, a categoria homem (hombre / homme / Mensch) "ser humano". As quatro definiçôes, portanto, correspondem a uma verdade comprovada no mundo. Além disso, verifica-se o estabelecimento de uma equivalência entre definiendum e definiens.

Ainda no que concerne às paráfrases transcritas ad supra, não obstante o modelo teórico (aparentemente) adotado seja extensional, a formulação em metalinguagem de conteúdo evidencia que se trata de uma paráfrase intensional. Isso, longe de representar uma contradição, corrobora a afirmação de que o definiens corresponde à intensão (sentido, em termos fregeanos) do definiendum. Além disso, o exposto no parágrafo precedente deixa claro que definiens e definiendum compartilham do mesmo referente (novamente em termos fregeanos), o que assegura o viés extensional das paráfrases em questão.

Finalmente, o fato de que cada uma das definiçóes tenha selecionado um conjunto distinto de traços é importante, na medida que antecipa uma das limitações do modelo em questão, já apontada por Taylor (2009, p. 35-39). Referimo-nos ao problema da delimitação dos traços necessários e suficientes de uma dada categoria, do qual trataremos na próxima subseção.

Nesse ponto da discussão, devemos alertar que o estabelecimento de uma correspondência 1:1 entre a formulação genus proximum + differencia spcificae e a semântica das condiçóes de verdade seria precipitada. Analisemos a seguinte paráfrase: 
$\operatorname{cobra}^{1}[\ldots]$ 1. [...] design. comum aos répteis escamados, carnívoros, da subordem das serpentes, de corpo alongado, membros e aberturas dos ouvidos ausentes, olhos imóveis e sem pálpebras, cobertos por escamas transparentes, língua delgada, bífida e protrátil e dentes cônicos, presentes na maxila, mandíbula e no teto da boca [...] (HouE, 2009).

Nesse caso, não temos uma definição por genus proximum + differentiae specificae. Aliás, não temos sequer uma paráfrase em metalinguagem de conteúdo. Entretanto, uma vez mais, o modelo teórico que parece subsidiar a formulação da definição é a semântica das condições de verdade, visto que a paráfrase expressa uma tentativa de categorização.

No sentido inverso, a herança aristotélica, notável no âmbito da lexicografia, não está atrelada apenas ao modelo das condições de verdade. Assim, pois, de acordo com Lara (1996, p. 209),

o estruturalismo 'descobriu', por assim dizer, que as notas definitórias da teoria aristotélica correspondiam a seus 'traços significativos mínimos e pertinentes' ou semas, e adotou a definição aristotélica modificando seus termos: a fórmula do significado ou semema aparecia encabeçada por um primeiro traço, o classema ou marcador semântico - segundo a concepção: européia ou anglo-americana - correspondente ao gênero próximo, e era seguida por uma série de semas equiparáveis à diferença específica, as propriedades e os acidentes da teoria aristotélica. ${ }^{20}$

Dessa forma, a análise componencial do significado (cf. POTTIER, 1977) toma forma no dicionário, utilizando-se da fórmula aristotélica. A definição por genus proximum + differentiae specificae, nesse caso, compõe-se de um termo descritor, que é um hiperônimo da unidade definida (genus proximum), e um ou mais especificadores, que cumprem a função de caracterizá-la, diferenciando-a dos seus co-hipônimos (differentiae specificae) (cf. MARTÍNEZ DE SOUZA, 1995, s.v. definición hiperonimica). Comparemos as paráfrases a seguir com aquelas apresentadas anteriormente:

\footnotetext{
${ }^{20}$ [el estructuralismo 'descubrió', por así decirlo, que las notas definitorias de la teoría aristotélica correspondían a sus 'rasgos significativos mínimos y pertinentes' o semas, y adoptó la definición aristotélica modificando sus términos: la fórmula del significado o semema iba encabezada por un primer rasgo, el clasema o marcador semántico según la concepción: europea o angloamericana - correspondiente al género próximo, y la seguía una serie de semas equiparables a la diferencia especifica, las propiedades y los accidentes de la teoría aristotélica]. Os destaques estão no texto original.
} 
$\operatorname{man}[\ldots] 1[\mathrm{C}]$ an adult male human [...] (OALD, 2005).

woman [...] 1 [C] an adult female human [...] (OALD, 2005).

silla nombre femenino 1 asiento individual con patas y respaldo [...] (DUEAe, 2003).

sofá nombre masculino Asiento para más de una persona, com brazos y respaldo, cómodo y generalmente mullido [...] (DUEAe, 2003).

Ao contrário das definições redigidas em conformidade com os subsídios da semântica formal, as paráfrases elaboradas segundo os fundamentos da semântica estruturalista, pelo menos em princípio, não deveriam fazer referência direta à entidade extralinguística. Sem embargo, é difícil estabelecer uma oposição clara entre significado e referente - ou entre intensão e extensão - quando se trata de definir determinadas unidades léxicas que possuem referentes extralinguísticos bem delimitados (p.ex., os nomes de animais, plantas e frutos) ${ }^{21}$ Nesses casos, gerar definiçōes no âmbito de uma teoria semântica intensional (como a análise componencial) torna-se muito difícil. Isso, no entanto, não significa que a aplicação de uma teoria semântica de caráter extensional (como a semântica das condições de verdade, ou mesmo a teoria dos protótipos) permitirá necessariamente obter resultados mais satisfatórios.

Por fim, convém assinalar as diferenças entre as definições regidas pelos princípios da semântica das condições de verdade e as paráfrases formuladas com base no modelo prototípico. Apesar do caráter extensional de ambas as teorias, as divergências inconciliáveis em relação à forma como a categorização é vista em cada caso deixam-se notar na formulação das paráfrases definidoras:

Mensch $^{1}$ [...] 2. Ein Mann, e-e Frauod. ein Kindals Individuum [...] (LaGWDaF, 2008).

humanbeing [...] A human being is a man, woman, orchild. [...] (CCLDe, 2003).

clothes [...] Clothes are the things that people wear, such as shirts, coats, trousers, and dresses. (CCLDe 2003).

sweet[...] 2 Sweets are smalls weet things such as toffees, chocolates, and mints. [...] (CCLDe, 2003).

${ }^{21}$ A própria noção de virtuema já antecipa uma referência à entidade extralinguística (cf. POTTIER, 1977). 
As definições inspiradas na semântica cognitiva, em geral, fazem uso de enumeraçōes dos membros mais típicos da categoria, ${ }^{22}$ ao contrário das definiçôes subsidiadas pela semântica das condições de verdade, que apresentam os traços pertinentes à categoria referida. Em Farias (2009b), buscou-se uma associação das definições prototípicas a uma técnica definitória particular, denominada whole-sentence definition. Entretanto, essa hipótese merece ser reconsiderada, haja vista o fato de que a definição de Mensch, ${ }^{1}$ por exemplo, apesar de ostensivamente prototípica, não se adapta a esse modelo definitório.

\section{Limitações da semântica das condições de verdade na formulação das definições}

A aplicação da semântica das condições de verdade como modelo teórico subjacente à redação das paráfrases definidoras enfrenta três grandes desafios: (a) a formulação de definições que, sendo suficientes em relação à delimitação dos traços pertinentes à categoria, também sejam suficientemente elucidativas para o consulente; (b) o isolamento do conjunto suficiente de condiçôes necessárias para determinar a pertinência a uma dada categoria; e (c) a correspondência fiel à extensão da categoria definida. Os dois últimos problemas, aliás, estão intimamente relacionados.

Para entender a primeira limitação enumerada, analisemos as definições transcritas abaixo:

gato sm (latcattu) 1. Mamífero carnívoro doméstico da família dos Felídeos, de grande utilidade para a destruição de ratos (Feliscattus). (MiE, 1998).

morcego (ê) sm. Zool. Mamífero quiróptero. (MiAu, 2008).

morangasf. Bras. Bot. Planta cucurbitácea, variedade de abóbora. (MiAu, 2008).

${ }^{22}$ Outra característica é a presença, em muitos casos, de informações enciclopédicas nas definições. A título de ilustração, mencionamos picazuroba "Ave gallinácea parecida en el tamaño, forma y plumaje a la tórtola (Zenaidamaculata)” (DILE, 1997, s.v., ac.1) e taça "copo cilíndrico com haste, us. para beber vinho, champanhe, conhaque etc.” (HouE, 2009, s.v., ac.1). No âmbito da semântica cognitiva, o conhecimento linguístico e o conhecimento das "coisas" se confundem. 
Esses são bons exemplos de definições que refletem uma categorização (com uma ressalva à informação s.v. gato "de grande utilidade para a destruição de ratos"). Entretanto, do ponto de vista elucidativo, levando em conta o público-alvo dessas obras, que, provavelmente, não será alguém especializado em zoologia ou botânica, as três paráfrases são débeis. Ressalte-se, além disso, que MiAu (2008) é um dicionário dirigido eminentemente ao público escolar, o que torna ainda menos justificável uma definição como 'Mamífero quiróptero', por exemplo. Entretanto, nesses casos, os problemas apontados nas definições não podem ser creditados a uma limitação intrínseca ao modelo semântico que subjaz a sua redação. Como vimos logo no início desta seção, é possível apresentar paráfrases que respondam ao modelo das condições necessárias e suficientes com um poder elucidativo mais elevado.

O segundo problema arrolado diz respeito, de certa forma, à delimitação das informaçōes que devem ser apresentadas na definição, a fim de estabelecer uma relação de equivalência entre definiendum e definiens. Nesse sentido, de acordo com Kleiber (2004, p. 30),

Se por traço necessário pretende-se simplesmente dar a entender que todos os membros possuem esse traço, fica-se exposto à dificuldade da verificação. [...] A dificuldade é amplificada se se faz com que a universalidade resulte da necessidade [...] Consequentemente, se um traço não é compartilhado por todos os membros, esse traço não é necessário. ${ }^{23}$

Esse problema, como já mencionamos, afeta diretamente a capacidade de abrangência extensional da definição, como é possível observar nos exemplos a seguir:

linguiça [...] 1. Rubrica: alimentação. tripa recheada com toucinho e carne crua (esp. de porco), temperada e cortada em pedaços miúdos. [...] (HouE, 2009).

salame [...] variedade da charcutaria italiana, espécie de salsichão de carne de porco ou de boi, temperado e seco ao ar ou no fumeiro (HouE, 2009).

salsicha [...] 2 Rubrica: culinária. tripa que se enche com carne picada e temperada. [...] (HouE, 2009).

${ }^{23}$ [Si par trait nécessaire on entend simplement signifier que tous les membres possèdent ce trait, on s'expose à la difficulté de la vérification. [...] La difficulté est levée si l'on fait découler l'universalité de la necessite [...] Il reste par conséquent que, si tous les membres ne possèdent pas un trait, ce trait n'est pas un trait nécessaire] 
Nos três casos, os traços arrolados são necessários para caracterizar a pertinência de uma dada entidade a cada uma das categorias, respectivamente, linguiça, salame e salsicha. Entretanto, o conjunto desses traços não se revela suficiente para determinar a extensão de cada uma das categorias. Dessa forma, a definição de salsich $a$, por exemplo, poderia aplicar-se tanto à categoria salsicha, quanto à categoria linguiça.

Nas situações mencionadas, no entanto, seria possível reformular as definiçôes, a fim de conseguir identificar claramente cada uma das categorias. Quando lidamos com categorias que, do ponto de vista de uma semântica estrutural, poderíamos chamar de hiperonímicas (por exemplo, mamiffero, réptil, ave), determinar o conjunto de condiçôes suficientes para caracterizálas torna-se mais complicado. Nesse ponto, não podemos deixar de evocar a crítica feita pela semântica cognitiva a respeito da rigidez da categorização no âmbito da semântica formal. Propomos analisar a seguinte definição:

ave $n$. $f$. animal vertebrado, ovíparo, de sangue quente e respiração pulmonar, com bico córneo, desprovido de dentes, cujo corpo revestido de penas está adaptado ao vôo [...] (DILP, 2010).

Essa definição reúne um conjunto de condições suficientes para caracterizar a pertinência à categoria ave. Entretanto, o traço 'estar apta ao voo' não corresponde a uma condição necessária para todos os membros incluídos na categoria ave. Pinguins e avestruzes não voam; galinhas, por sua vez, tampouco poderiam ser caracterizadas pela propriedade de voar. Entretanto, o traço 'estar apta ao voo' é uma característica que está, indubitavelmente, associada à categoria ave.

\section{Considerações finais}

Entre as principais contribuições da semântica das condições de verdade à redação das definições está o privilégio conferido ao viés extensional. Ainda que não haja uma diferença substancial em relação à formulação linguística das paráfrases subsidiadas, respectivamente, pelo modelo estruturalista e pelo modelo formal, cada teoria assume pontos de vista divergentes. No primeiro caso, delimita-se um significado no interior de uma língua funcional a partir dos traços semânticos (semas) que compõem o semema. No segundo caso, delimita-se uma categoria em oposição às demais no mundo extralinguístico, em função dos traços compartilhados entre seus membros. Por outro lado, comparando-se o modelo formal ao cognitivo, apesar de ambos compartirem 
uma "visão extensional" do significado (entendendo-se "extensão" como "referente"), a principal diferença reside na formulação da definição. Assim, uma paráfrase que obedeça aos princípios da teoria dos protótipos privilegiará a enumeração dos membros mais prototípicos de uma categoria, enquanto uma paráfrase formulada sob os princípios da semântica formal procura delimitar o conjunto de traços suficientes para caracterizar uma determinada classe.

A aplicação da semântica das condições de verdade à definição, no entanto, enfrenta alguns problemas, que são, na verdade, derivados das limitações apontadas na teoria clássica da categorização. Entretanto, assim como a semântica das condiçóes de verdade, a análise componencial e a teoria dos protótipos tampouco são capazes de responder satisfatoriamente a todas as demandas relativas ao processo de elaboração das definições nos dicionários de língua.

Por fim, como consideração geral, destacamos que, segundo Geeraerts (1987), não existe uma base teórica clara que sustente, de forma integral, a concepção dos dicionários. Prova disso é o fato de que, em uma mesma obra, encontramos paráfrases que parecem estar orientadas por modelos teóricos completamente divergentes (p.ex., LaGWDaF, 2008, s.v. Mensch, ${ }^{1}$ ac. 1 e 2). Ademais, não é possível sequer assegurar que o lexicógrafo tenha "optado" conscientemente por uma determinada teoria no momento de formular as definiçōes (cf. FARIAS, 2009b).

\section{Referências bibliográficas}

ALLWOOD, J. et al. Logic in Linguistics. Cambridge: CUP, 2001.

ARISTÓTELES. Órganon. Tradução Edson Bini. 2. ed. Bauru: EDIPRO, 2010.

BALDINGER, K. Alphabetisches oder begrifflich gegliedertes Wörterbuch? In: ZGUSTA, L. (Hrsg.). Probleme des Wörterbuchs. Darmstadt: WBG, 1985. p.40-57. BOSQUE, I. Sobre la teoría de la definición lexicográfica. Verba, Santiago de Compostela, v.9, p. 105-123, 1982.

BUGUEÑO MIRANDA, F. Notícia sobre o comentário de forma e comentário semântico em um dicionário de falsos amigos espanhol-português. Expressão, Santa Maria, v. 8, n. 1, p. 89-93, 2004.

BUGUEÑO MIRANDA, F. Para uma taxonomia de paráfrases explanatórias. Alfa, São Paulo, v.53, n.1, p.243-260, 2009.

BUGUEÑO MIRANDA, F; FARIAS, V. S. Informaçōes discretas e discriminantes no artigo léxico. Cadernos de Tradução, Florianópolis, n.18, p.115-135, 2006. 
BUGUEÑO MIRANDA, F.; FARIAS, V. S. Desenho da macroestrutura de um dicionário escolar de língua portuguesa. In: BEVILACQUA, C. R.; HUMBLÉ, Ph.; XATARA, C. M. (Org.). Lexicografia Pedagógica: Pesquisas e perspectivas. Florianópolis: UFSC / NUT, 2008. p.129-167. Disponível em: <http:// www.cilp.ufsc.br/LEXICOPED.pdf>. Acesso em: 25 out. 2008.

BUGUEÑO MIRANDA, F.; FARIAS, V. S. Panorama crítico dos dicionários escolares brasileiros. Lusorama, Frankfurt am Main, v. 77 / 78, p. 29-78, 2009. BUGUEÑO MIRANDA, F; FARIAS, V. S. Princípios para o desenvolvimento de uma teoria da definição lexicográfica. Alfa, São Paulo, v. 55, n. 1, p. 31-61, 2011 a. BUGUENTO MIRANDA, F.; FARIAS, V. S. Sobre las palabras y su clasificación según su contenido. Los problemas para el lexicógrafo. Revista de Filología, La Laguna, v. 29, p. 9-19, 2011 b.

CARNAP, R. Meaning and Necessity. A Study in Semantics and Modal Logic. 2. ed. Chicago / London: The Universityof Chicago Press, 1988.

CCLDe. SINCLAIR, J. (Ed.). Collins COBUILD Advanced Learner's Dictionary. Glasgow: Harper Collins, 2003.

CHIERCHIA, G.; McCONELL-GENET, S. Meaning and grammar. 2. ed. Cambridge: MIT Press, 2000.

COSERIU, E. Sistema, norma y habla. In: COSERIU, E. Teoría del lenguaje y lingüistica general. Cinco estudios. 2. ed. Madrid: Gredos, 1967. p.11-113.

DILE. GILI GAYA, S.; ALVAR EZQUERRA, M. Vox Diccionario General de la Lengua Española Ilustrado. Barcelona: Bibliograf, 1997.

DILP. Dicionário Ilustrado da Lingua Portuguesa. Porto: Porto Editora, 2010.

DPRAE. REAL Academia Española. Diccionario práctico del estudiante. Barcelona: Santillana, 2007.

DUBOIS, J.; DUBOIS, C. Introduction à la lexicographie: le dictionnaire. Paris: Larousse, 1971.

DUEAe. VOX. Diccionario de uso del español de América y España. Barcelona: SPES Editorial, 2003.

DUEe. MOLINER, M. Diccionario de uso del español. Madrid: Gredos, 2001. DUPUY-ENGELHARDT, H. Zur Beschreibung lexikalischer Bedeutung. In: HOINKES, U. (Hrsg.). Panorama der lexikalischen Semantik. Tübingen: Narr, 1995.

ENGELBERG, S.; LEMNITZER, L. Lexikographie und Wörterbuchbenutzung. 2. ed. Tübingen: Stauffenburg, 2004. 
EVANS, V.; GRENN, M. Cognitive Linguistics: An introduction. London: Lawrence Elrbaum, 2006.

FARIAS, V. S. Desenho de um dicionário escolar de lingua portuguesa. 2009. 285 f. Dissertação (Mestrado em Letras) - Instituto de Letras, Universidade Federal do Rio Grande do Sul, Porto Alegre, 2009a.

FARIAS, V. S. Whole-sentence definition versus definição por genus proximum + differentiae specificae: Um contraste entre duas técnicas definitórias. Estudos da Linguagem, Belo Horizonte, v.17, n.1, p.73-100, 2009b.

FREGE, G. Über Sinn und Bedeutung. In: PATZIG, G. (Hrgs.). Funktion, Begriff, Bedeutung. Fünflogische Studien. Göttingen: Vandenhoeck \& Ruprecht, 2008.

GEERAERTS, D. Types of Semantic Information in Dictionaries. In: ILSON, R. (Ed.). A spectrum of lexicography. Amsterdam: John Benjamins, 1987. p. 1-9.

GEERAERTS, D. The definitional practice of dictionaries and the Cognitive Semantic conception of polysemy. Lexicographica, v. 17, p. 6-21, 2001.

GEERAERTS, D. Meaning and definition. In: STERKENBURG, P. (Ed.). $A$ practical guide to lexicography. Amsterdam / Philadelphia: John Benjamins, 2003. p.83-93.

HAENSCH et al. La lexicografia. De la lingüistica teórica a la lexicografía práctica. Madrid: Gredos, 1982.

HARTMANN, R. Teaching and Researching Lexicography. London: Longman, 2001.

HARTMANN, R.; JAMES, G. Dictionary of Lexicography. London / New York: Routledge, 2001.

HAUSMANN, F. J.; WIEGAND, H. E. Component Parts and Structures of General Monolingual Dictionaries: A survey. In: HAUSMANN, F. J. et al. (Hrsgn.). Wörterbücher, dictionaries, dictionnaires. Ein internationales Handbuch zur Lexikographie, Band 1. Berlin / New York: Walter de Gruyter, 1989. p.328-360.

HILTY, G. Komponentenanalyse und Prototypensemantik. In: HOINKES, U.; DIETRICH, W. (Hrsgn.). Kaleidoskop der lexikalischen Semantik. Tübingen: Narr, 1997. p. 63-69.

HouE. HOUAISS, A. Dicionário Houaiss da língua portuguesa. Rio de Janeiro: Objetiva, 2009.

JACKSON, H. Lexicography. An introduction. London / New York: Routledge, 2002.

KLEIBER, G. La sémantique du prototype. Catégories et sens lexical. Paris: PUF, 2004. 
LANDAU, S. Dictionaries. The art and craft of lexicography. 2. ed. Cambridge: CUP, 2001.

LARA, L. F. Teoría del diccionario monolingüe. México, D.F.: El Colegio de México / Centro de Estudios Lingüísticos y Literarios, 1996.

LaGWDaF. GOETZ, D. et al. Langenscheidt Groâworterbuch Deutsch als Fremdsprache. Berlin / München: Langenscheidt, 2008.

LYONS, J. Semantics, v.1. Cambridge: CUP, 1989.

MARTÍNEZ DE SOUZA, J. Diccionario de lexicografia práctica. Barcelona: Bibliograf, 1995.

MEDINA GUERRA, A. M. La microestructura del diccionario: la definición. In: MEDINA GUERRA, A. M. (Coord.). Lexicografía española. Barcelona: Ariel, 2003. p.127-150.

MiAu. FERREIRA, A. B. de H. Miniaurélio: o dicionário da língua portuguesa. 7. ed. Curitiba: Positivo, 2008.

MiE. MICHAELIS. Moderno dicionário da língua portuguesa. São Paulo: Melhoramentos, 1998.

NDW. GOETTERT, K-H. Neues Deutsches Wörterbuch. Köln: Helmut Lingen, 2007.

OALD. HORNBY, A. S. Oxford Advanced Learner's Dictionary. 7. ed. Oxford: OUP, 2005.

PALMER, F. R. Semantics. 2. ed. Cambridge: CUP, 2001.

PCDIt. Parola Chiave: dizionario di italiano per brasiliani. São Paulo: Martins Fontes, 2007.

POTTIER, B. A definição semântica nos dicionários. Tradução Maria Angela Botelho Pereira. In: LOBATO, L. M. P. (Org.). A semântica na lingüistica moderna: o léxico. Rio de Janeiro: Francisco Alves, 1977. p. 21-31.

PRobE. Nouveau Petit Robert: Dictionnaire alphabétique et analogique de la langue française. Paris: Le Robert, 2001.

REY, A. Le lexique: images et modèles. Du dictionnaire à la lexicologie. Paris: Armand Colin, 1977.

ROSCH, E. Principles of categorization. In: ROSCH, E.; LLOYD, B. B. (Ed.). Cognition and categorization. Hillsdale, N.J.: Lawrence Erlbaum, 1978. p. 27-48. RUNDELL, M. More than one way to skin a cat: Why full-sentence definitions have not been universally adopted. In: FONTENELLE, T. (Ed.). Practical lexicography: A reader. Oxford: OUP, 2008. p. 197-209.

SECO, M. Estudios de Lexicografia Española. 2. ed. Madrid: Gredos, 2003. 
SVÉNSEN, B. Practical lexicography. Principles and methods of dictionary-making. Oxford: OUP, 1993.

TARSKI, A. The Semantic Conception of Truth: and the Foundations of Semantics. Philosophy and Phenomenological Research, v.4, n.2, p.341-376, 1944. TARSKI, A. Introduction to the Logic and the Methodology of Deductive Sciences. Tradução Olaf Helmer. 2.ed. New York: OUP, 1995.

TAYLOR, J. R. Linguistic categorization. 3.ed. Oxford: OUP, 2009.

WEINRICH, H. A verdade dos dicionários. In: VILELA, M. (Org.). Problemas da lexicologia e lexicografia. Tradução Mário Vilela. Porto: Livraria Civilização, 1979. p. 314-337.

WIEGAND, H. E. Der Begriff der Mikrostruktur: Geschichte, Probleme, Perspektiven. In: HAUSMANN, F. J. et al. (Hrsgn.). Wörterbücher, dictionaries, dictionnaires. Ein internationales Handbuch zur Lexikographie, Band 1. Berlin I New York: Walter de Gruyter, 1989a. p.409-462.

WIEGAND, H. E. Arten von Mikrostrukturen im allgemeinen einsprachigen Wörterbuch. In: HAUSMANN, F. J. et al. (Hrsgn.). Wörterbücher, dictionaries, dictionnaires. Ein internationales Handbuch zur Lexikographie, Band 1. Berlin I New York: Walter de Gruyter, 1989b. p.462-501.

WITTGENSTEIN, L. Philosophische Untersuchungen. Frankfurt am Main: Suhrkamp Verlag, 2003.

ZGUSTA, L. Manual of Lexicography. Prague / Paris: Academia / Mouton, 1971. 